\title{
Ecological impacts of an invasive mesopredator do not differ from those of a native mesopredator: lionfish in Caribbean Panama
}

\author{
Jameal F. Samhouri ${ }^{1,1}$ (D) Adrian C. Stier ${ }^{2,1}$
}

Received: 12 September 2020/ Accepted: 10 June 2021/Published online: 4 July 2021

(C) This is a U.S. government work and not under copyright protection in the U.S.; foreign copyright protection may apply 2021

\begin{abstract}
The impacts of invasive lionfish (Pterois volitans/miles) on native coral reef populations in the Western Atlantic Ocean and Caribbean Sea can be enormous. However, how much lionfish differ from native predators and whether their effects outweigh the abundant mesopredators that occupy many reefs invite continued examination. Here, we present empirical evidence from Caribbean Panama and beyond suggesting that lionfish are less abundant than native mesopredators. Furthermore, we show that their direct impacts on survivorship and size distributions of one native prey species are similar to those of a native mesopredator. These results support calls for lionfish management that considers evolving local ecological and social dynamics, including prey community composition, the roles of native mesopredators, and regional goals for conservation and fisheries. Recognition of regional context creates the potential for synergies between conservation actions aimed both at the invasion and other consequential problems such as overexploitation and climate change.
\end{abstract}

Topic Editor Alastair Harborne

Jameal F. Samhouri and Adrian C. Stier contributed equally to this work.

Jameal F. Samhouri

jameal.samhouri@noaa.gov

1 Conservation Biology Division, Northwest Fisheries Science Center, National Marine Fisheries Service, National Oceanic \& Atmospheric Administration, Seattle, WA 98112, USA

2 Department of Ecology, Evolution, and Marine Biology, University of California, Santa Barbara, CA 93106, USA
Keywords Indo-pacific lionfish $\cdot$ Pterois volitans $\cdot$ Pterois miles - Invasive species · Naiveté · Coral reefs · Socialecological systems · Predation

\section{Introduction}

The ecological impacts of invasive species can have major economic, social, and cultural consequences (Pejchar and Mooney 2009). However, the effects of invasive species are not uniformly negative, and there is increasing attention to how the impact and function of invasive species can vary geographically (Davis et al. 2011; Lockwood and Robinson 2014; Doherty and Ritchie 2016). For example, in certain localities invasive plants can have null or positive effects on nesting native birds (Gleditsch and Carlo 2014). More generally, invasive species can offer novel socioeconomic opportunities (resource extraction, tourism; Pejchar and Mooney 2009). Quantifying the ecological and social significance of invasive species in different locations can facilitate an understanding of trade-offs between costly removals of invaders versus a more complex characterization of what it means to accept novel species in socialecological systems riddled by "wicked problems" (Rittel and Webber 1973).

On coral reefs, there are few examples of successful invasions by vertebrate predators. A conspicuous exception is the introduction of Indo-Pacific lionfishes (Pterois volitans and P. miles) to the Atlantic in the 1980s and their rapid spread in the 2000s. Invasive lionfish are voracious generalist predators with venomous spines that act as a built-in defense against native predators (Côté et al. 2013). Exponential increases in invasive lionfish abundance in some areas have raised serious conservation concerns for native prey communities (e.g., Ingeman 2016). The 
vulnerability of native communities to lionfish is likely compounded by a long history of overexploitation of apex predators. As in many ecosystems (Ritchie and Johnson 2009), the loss of apex predators on Caribbean reefs has caused an increase in the abundance of smaller predators such as small groupers and snappers (Stallings 2009). This increase in smaller predators, also known as mesopredators, threatens the abundance and biodiversity of coral reef fishes (Stier et al. 2017). The lionfish invasion may exacerbate these mesopredator threats given that lionfish can play a similar trophic role to native mesopredators (Albins 2013; Ellis and Faletti 2016; Curtis et al. 2017). For these reasons and others, there is a growing appreciation that the impacts of lionfish on native coral reef communities are likely to be heavily context-dependent, and mediated by the abundance, influences, and naiveté of native predators, competitors, and prey (Anton et al. 2016; Ingeman et al. 2017). However, there is an incomplete understanding of how lionfish abundance varies relative to native mesopredator abundance, and of the relative impacts of lionfish and native mesopredators on native prey species.

Here, we provide evidence from Caribbean Panama and beyond that lionfish are less abundant than native mesopredators and that lionfish impacts on one common prey species are indistinguishable from a native mesopredator. Our results provide support for the view that management of invasive lionfish may be succeeding in some places and that continuation of control efforts requires nuanced consideration in relation to specific conservation goals and in relation to other environmental concerns.

\section{Methods}

\section{Observational surveys}

We conducted two types of flashlight-assisted visual surveys at three different sites near Bocas del Toro, Panama (Punta Caracol, Casa Blanca, Casa Verde), in January 2015. First, we counted lionfish, native predators, and potential prey for these predators on 24 patch reefs. Two divers counted all non-cryptic fishes on each patch reef, which primarily consisted of the corals Orbicella spp. and Agaricia spp. Following surveys, divers measured the area of the reef approximated by the product of its maximum width and length in meters, compared their fish observations, and scored a predator species as present on a patch reef if at least one diver detected it. For prey, we averaged the counts of individuals $\leq 5 \mathrm{~cm}$ TL across divers. Patch reefs averaged $1-2 \mathrm{~m}^{2}$ in area (range: $0.3-3.3 \mathrm{~m}^{2}$ ), and those we surveyed were generally $2-10 \mathrm{~m}$ apart from one another. All surveys were conducted during the day, and flashlights were used to look inside dark crevices.
Second, we conducted timed roving diver surveys of lionfish and two types of native mesopredator, the graysby Cephalopholis cruentata and hamlets Hypoplectrus spp., at each site. In these surveys (which did not focus on individual patch reefs but rather the full matrix of habitat at each site), teams of three divers swam for $20 \mathrm{~min}$ each $\sim 1 \mathrm{~m}$ above the substrate and along consistent depth contours of $4 \mathrm{~m}$ and $8 \mathrm{~m}$. Counts focused on the mesopredators sighted directly below each diver and were summed within a team of divers to compare predator abundances (Table S1).

We conducted three analyses to quantify whether native mesopredators were more common than invasive lionfish. First, we tested the hypothesis that invasive and native mesopredators occupied an equal proportion of reefs by analyzing a generalized linear mixed model (logit link, binomial distribution) of occurrence as a function of predator type (native or invasive), with site as a random effect. Second, we tested the hypothesis that native and invasive mesopredators differed in conditional density (i.e., density when present). Because not all mesopredator species were present at all sites, we pooled all native mesopredators together and compared the conditional density of native mesopredators to lionfish using a Student's $t$-test. Third, we tested the hypothesis that invasive and native mesopredators were equally abundant during the timed surveys at the three sites by comparing mesopredator abundance across observer teams using a one-way ANOVA with survey sites as the replicates.

In the patch reef surveys, one prey species, the masked goby Coryphopterus personatus, was conspicuously more abundant than other prey species, forming large shoals above individual reefs where we observed multiple predator species stalking and striking them. To test the hypothesis that the masked goby was more abundant than all other prey species summed together, we analyzed a generalized linear mixed model of log-transformed densities to compare these two groups, using site as a random effect.

Because our predator surveys in Panama reflect a snapshot in time from one region, we also analyzed observational data from the Reef Environmental Education Foundation (www.reef.org) database, collected during surveys conducted across eight regions in the Caribbean and Western Atlantic in the six years leading up to our study 2010-2015. The REEF database compiles information from volunteer divers who use a roving diver technique to count all fishes observed during a dive, as well as metadata including location, date, time, and habitat. Expert density is a weighted average index based on the frequency of observations by expert REEF divers in different abundance categories $(1,2-10,11-100,>100$ individuals). A dive without any reported sighting of a fish species is 
interpreted as 0 individuals for that dive. We used a Welch's two-sample $t$-test to compare expert densities of lionfish and graysby, treating regional means from 2010 to 2015 as replicates (Table S2).

\section{Experimental test of lionfish and native mesopredator impacts}

In January-February 2015, we conducted a laboratory experiment to test whether the direct effects of lionfish on native masked gobies differed from the effects of the native graysby, in Bocas del Toro, Panama, at the Smithsonian Tropical Research Institute. ${ }^{1} \mathrm{We}$ focused on this prey species because it was highly abundant and we observed lionfish and native mesopredators feeding voraciously on these gobies in the field. The experiment consisted of three trials, each of which included four treatments within replicate aquaria: empty control (10 gobies only), nonmesopredator control (1 parrotfish Scarus iseri with 10 gobies); native mesopredator (1 graysby with 10 gobies); and invasive predator (1 lionfish with 10 gobies; see Table S3 for sample sizes by trial). The laboratory experiment matched observed mesopredator densities, as when a graysby or lionfish was present on a patch reef at our study sites, it was uncommon to observe more than one. We collected fish from nearby reefs and allowed them to acclimate to the laboratory for $\geq 24 \mathrm{~h}$ prior to initiating experiments. We standardized mesopredator satiation by ensuring that individuals did not feed for $\geq 24$ prior to inclusion in the feeding trials.

Each aquaria contained a single PVC tube $(15 \mathrm{~cm}$ long, $2.5 \mathrm{~cm}$ diameter) to provide structure. At 1200 on the day of each trial, we introduced the mesopredators or parrotfish to aquaria. Trials began at 1630 when we introduced gobies to the aquaria (haphazardly with respect to goby size). We note that lionfish activity peaks during twilight periods in both their native and non-native ranges (Green et al. 2011; Cure et al. 2012; McCallister et al. 2018, but see Morris and Akins 2009). At 1830, we removed mesopredators/parrotfish from the experimental aquaria and placed them in larger holding tanks until the subsequent trial. We collected, counted, and measured (SL mm) surviving gobies from each tank the following morning.

To test the hypothesis that lionfish influenced the overall and size-selectivity of mortality of gobies differently than native mesopredators, we conducted nonparametric Kruskal-Wallis tests with proportion mortality or size of surviving gobies as the response variable and predator treatment as the predictor variable. Nonparametric tests were necessary because of the extreme differences in data

\footnotetext{
${ }^{1} \mathrm{https} / /$ stri.si.edu/facility/bocas-del-toro
}

distribution in the control treatments (very low mortality) and the mesopredator treatments (higher mortality). We pooled data across three temporal trials and across empty control and non-predator control treatments, as the differences between lionfish, graysby, and control treatments during each trial, and results for empty control and nonpredator control treatments, were qualitatively similar. Because in some treatments there were an abundance of replicates without any predation, while in the mesopredator treatments approximately half of the fish were eaten, the data violated assumptions of normality and homogeneity of variance for parametric statistics. We used a Wilcox post hoc test to determine if response variables differed significantly between the native and invasive mesopredator treatments. All analyses were performed using R software (R Core Team 2020).

\section{Results and discussion}

We encountered significantly fewer lionfish than native mesopredators in Caribbean Panama, on both the patch reefs (occurrence: Fig. 1a; glmer $Z=2.356, p=0.019$; conditional density: Fig. $1 \mathrm{~b} ; t$-test, $=2.803, p=0.015)$ and during timed mesopredator survey counts (Fig. 1c; ANOVA, $F=8.877, p=0.016)$. On average, native mesopredators occupied $>2 \times$ as many patch reefs as lionfish (range: 1-fourfold differences), their conditional densities were $\sim 50 \%$ greater, and they were 30-40 times more abundant during timed counts (Table S1). Relatively low occurrence, density, and abundance of lionfish in our study may reflect successful efforts to cull lionfish via fishing derbies (Malpica-Cruz et al. 2016; Green et al. 2017), effective biotic control by the native fish assemblage (Ellis and Faletti 2016), and/or a tapering of the invasion wave (Benkwitt et al. 2017). We do not have data to speak directly to lionfish control efforts in Caribbean Panama, though anecdotal evidence ${ }^{2}$ and reports in conference proceedings suggest that derbies and fisheries by Ngobe indigenous people have reduced lionfish densities in this region (Fehr et al. 2012; ICRI 2014).

Our local finding in Caribbean Panama appears to generalize: comparison of graysby and lionfish densities across eight regions in the Western Atlantic and Caribbean suggests that graysby densities are $\sim 20 \%$ higher on average (Fig. 1d; Welch's $t=2.44$, df $=11.25, p=0.033$ ). These results are consistent with observations from several other studies in the western Caribbean (Elise et al. 2014; Hackerott et al. 2017; Peiffer et al. 2017), which have described much lower lionfish abundance than in locations farther north and east (Green et al. 2012). These geographic

\footnotetext{
${ }^{2}$ http://www.tropicalcc.org/lionfish-control-management
} 

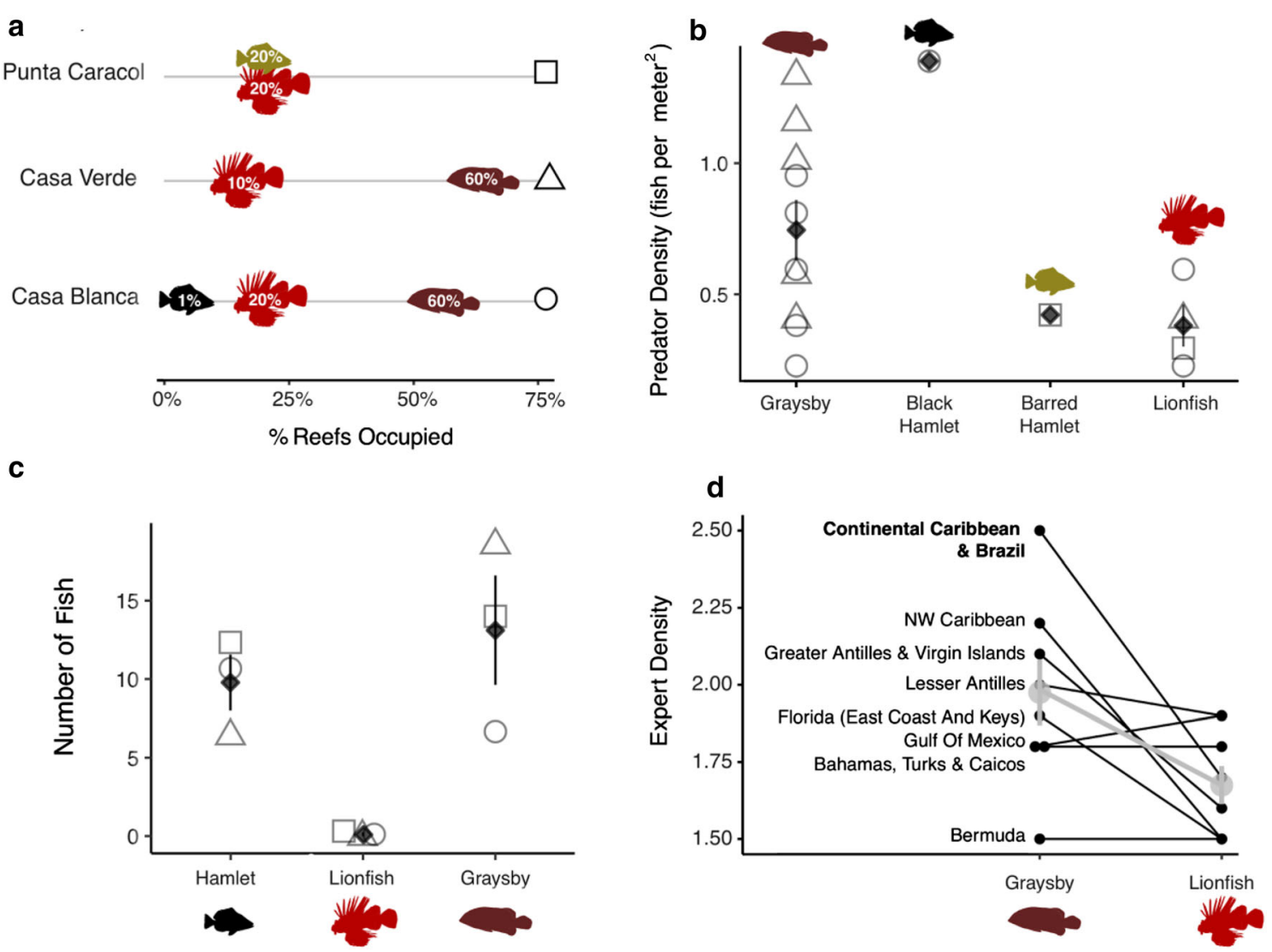

Fig. 1 Comparison of a the percentage of patch reefs (Punta Caracol: $n=5$; Casa Blanca: $n=11$; Casa Verde: $n=8$ ) occupied by native mesopredators (graysby Cephalopholis cruentata and hamlets $\mathrm{Hy}$ poplectrus puella, H. nigricans) and Indo-Pacific lionfish (Pterois volitans and $P$. miles), $\mathbf{b}$ the density of native mesopredators and lionfish when present on those patch reefs, $\mathbf{c}$ the number of native mesopredators and lionfish observed on timed, roving diver surveys,

and $\mathbf{d}$ the expert densities (derived from the REEF database) of one native mesopredator (the graysby) and lionfish across eight regions in the Caribbean and Western Atlantic from 2010 to 2015. Panels ac focus on three sites in Caribbean Panama (Punta Caracol, squares; Casa Verde, triangles; Casa Blanca, circles) surveyed in 2015. Filled symbols in b-d reflect means $\pm 1 \mathrm{SE}$ across sites/regions

differences may imply disparities in lionfish control efforts, carrying capacities, or ecological interactions (Ingeman et al. 2017). One hypothesis associated with disparities in ecological interactions is that lionfish prefer patch reef habitats or show higher growth, survival, and immigration on patch reefs, compared to contiguous reef habitats. We note that the highest density of lionfish recorded in the invaded range comes from artificial reefs in the northeastern Gulf of Mexico (Dahl and Patterson 2014) and that many studies in the northeastern Caribbean have focused on patch reef habitats (e.g., Green et al. 2011; Albins 2013; Ingeman 2016). While we do not have information about the characteristics of the reef matrix at each of the REEF study sites (Fig. 1d), our own observations from Caribbean Panama are consistent with the hypothesis that habitat configuration (cf. Sandin and Pacala 2005; White et al. 2011) plays a role in lionfish population dynamics: invasive lionfish were less common than native mesopredators on the patch reefs we surveyed (Figs. 1ab), but they were

even less common and rarely observed at all on roving diver surveys across contiguous reef habitat (Fig. 1c).

Our results demonstrate that lionfish are less common than native mesopredators in Caribbean Panama and beyond, but it is possible that lionfish impacts on native prey are greater (Albins 2013; Ellis and Faletti 2016). We tested this hypothesis using the masked goby as a focal prey species, which occurred in shoals of 10-100 s of individuals with densities $\geq$ tenfold those of all other prey species combined $(t=13.365, p<0.001$; Fig. S1).

Goby mortality was higher in the invasive and native mesopredator treatments compared to the control $\left(\mathrm{K}-\mathrm{W} \chi^{2}\right.$ $=17.73, p=0.001)$. While all gobies survived in the control treatments, on average $\sim 50 \%$ of them survived the 2-h experimental trials in both the invasive lionfish and native graysby treatments (Fig. 2a), mortality rates that were statistically indistinguishable (Wilcox post hoc test $=81.5, p=0.66)$. Furthermore, the size selectivity of predation by invasive and native mesopredators did not differ from each other or from the control treatment $(\mathrm{K}-\mathrm{W}$ 
$\chi^{2}=2.56, p=0.28$; Fig. $2 b$ ). Though replication was limited with our experimental design, we found strong congruence in outcomes across trials, giving little reason to suspect that more replication would lead to different inferences. Furthermore, these results are consistent with a recent meta-analysis of field experiments (Stier et al. 2017), which found that the effect of lionfish predation on native prey communities is consistently negative and strong, but statistically identical to predation effects induced by native mesopredators.

In contrast to our findings, the one direct, field-based experimental test of native mesopredator and lionfish impacts on native prey mortality (in the Bahamas) demonstrates that lionfish effects are stronger than native mesopredators for many species (Albins 2013). This difference could result from several factors. For instance, lionfish and native mesopredators may exhibit geographically distinct effects on native prey communities because of the higher lionfish densities in the Bahamas compared to Panama (Fig. 1d; Green et al. 2014) or due to enhanced biotic resistance closer to the equator (Freestone et al. 2013 but see Anton et al. 2019). In addition, vulnerability of gobies to lionfish predation may be low; Albins (2013, Table 1) shows weak or positive impacts of lionfish on three of the five gobies examined in that study. Similarly, separate experimental evidence suggests that two species of Caribbean gobies (Coryphopterus glaucofraenum and Gnatholepis thompsoni), including one congener of the masked goby, show a moderate level of recognition of lionfish as a predation threat (Marsh-Hunkin et al. 2013). While prey naiveté toward lionfish has been shown to be an important ecological mechanism behind the invasion success of lionfish in the Caribbean and the eastern Mediterranean (Côté et al. 2013; Anton et al. 2016; Haines and Côté 2019; D’Agostino et al. 2020), this mechanism does not appear to be a strong factor for gobies and it is possible that past co-evolutionary history between the $\mathrm{Co}$ ryphopterus genus and the Pterois genus has dampened the impact of naiveté.

Alternatively, our findings may contrast with the longer and broader field study undertaken by Albins (2013) due to the short-term nature, confined laboratory environment, restricted time of day, and singular prey species we employed for predation trials. While there are several inferential advantages of a field experiment, additional field- and lab-based experimental studies in different geographies and with different prey species will clarify the relative influences of invasive lionfish and native mesopredators on native prey. Strong effects of lionfish are less likely in locations with low densities of invasive lionfishas in the present study (Fig. 1) -but also where there is a high standing biomass of fishes and larger size classes of fishes (Ingeman et al. 2017). Additional experimental work to understand how these factors interact to influence lionfish impacts on native communities will allow for more targeted, effective control efforts (cf. Green et al. 2014). Inconsistency of results across prey species, studies, and regions is not without precedent in the study of invasive species and emphasizes the need to evaluate how shortterm impacts of invaders over small geographic areas scale to entire ecosystems in the medium to long terms after an initial invasion wave (Lockwood and Robinson 2014).

No matter their relative influence, in absolute terms both native mesopredators and invasive lionfish drive shifts in the abundance and biodiversity of Western Atlantic and Caribbean coral reef fish communities (Stier et al. 2017). These effects are partially a result of disproportionately high fishing rates of apex predators that have allowed for mesopredator release (Stallings 2009), a widespread phenomenon on coral reefs and in other ecosystems (Ritchie and Johnson 2009). It remains an open question whether lionfish are exacerbating widespread mesopredator release in the Western Atlantic and Caribbean by adding another highly abundant species to this guild, or if they are competing and partially or wholly replacing contemporary functional roles of native mesopredators. No matter where reality lies, emerging studies showing the potential for native apex predators to inhibit lionfish (Mumby et al. 2011; Diller et al. 2014; Ellis and Faletti 2016) suggest that restoration of native apex predators may offer significant promise to address mesopredator release and the lionfish invasion simultaneously (Doherty and Ritchie 2016). However, additional research on the interactions between lionfish and native predators is needed to understand the context under which native predators may mediate the effects of lionfish (Hackerott et al. 2013).

The evidence synthesized here embraces recent calls for critical examination of claims about the consequences of invasive taxa more generally (Davis et al. 2011). Our study also underscores the role time and spatial scale play in shaping the impacts of species introductions (Lockwood and Robinson 2014) and suggests that geographic differences and trends in lionfish impacts are evolving. Given that in Caribbean Panama lionfish are uncommon compared to native mesopredators and have similar effects on at least one of the most common native prey species, current management practices to control lionfish may be considered quite effective. Alternatively, given the generally low relative abundance of lionfish, they may be well thought of as leverage points to address "wicked problems" such as climate change and overexploitation (Rittel and Webber 1973) also affecting coral reefs in the region. For example, the social and economic opportunities provided by the emergence of lionfish as a new source of food, livelihoods, and tourism remain largely unexamined (but 
Fig. 2 The a mortality and b size distribution of native prey (Coryphopterus personatus) exposed to native mesopredator (graysby), invasive mesopredator (lionfish), and control treatments in mesocosm experiments. In a, black points and error bars represent mean proportional mortality $\pm 95 \%$ $\mathrm{CI}$, and colored triangles represent results from individual replicate aquaria for each treatment. In b, density plots show the smoothed distribution of the points along the numeric axis of survivor length and hash marks on $x$-axis reflect size of individual survivors from each treatment, pooled across trials and aquaria. The peaks of the density plots are at the locations where there is the highest concentration of points
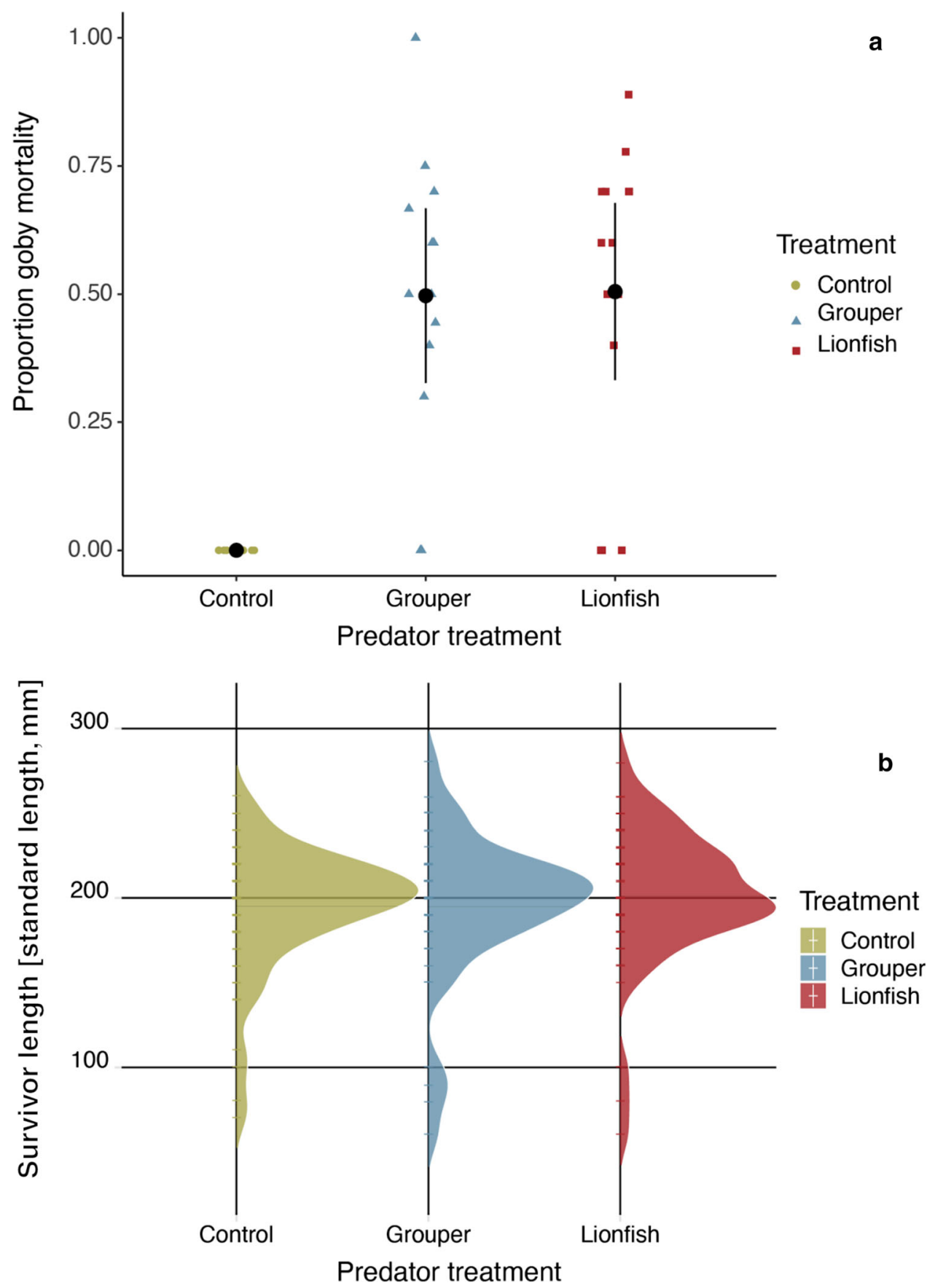

see Chapman et al. 2016), but could be important in areas where the status of fisheries is poor, food security is low, and vulnerability to climate change is high (Siegel et al. 2019). On the other hand, if lionfish depress densities of native herbivores that graze algae sufficiently, they may aggravate the challenges already faced by corals due to fishery removals (Bellwood and Goatley 2017), which would inspire a redoubling of control efforts where local economies are heavily dependent on reef-based tourism. We encourage future efforts to build a place-based understanding of the ecological, economic, and social links to lionfish in Panama and throughout their introduced range.

Supplementary InformationThe online version contains supplementary material available at https://doi.org/10.1007/s00338021-02132-8.

Acknowledgements Craig Layman, John Bruno, Kurt Ingeman, Blake Feist, Joe Curtis, Julian Olden, Melissa Poe, and four anonymous reviewers provided helpful comments on earlier versions of this manuscript. We also gratefully acknowledge the entire 3 Seas XXX and XXXI classes for their work on this study, as well as Sebastian, 
Fufo, Abuelo, Aqualounge, and all the odd-numbered breeding hamlets that got away.

\section{Declarations}

Conflict of interest The authors declare that they do not have conflict of interest.

Ethical statement We certify that this article was prepared as part of our official duties. The article is thus in the public domain and cannot be copyrighted.

Open Access This article is licensed under a Creative Commons Attribution 4.0 International License, which permits use, sharing, adaptation, distribution and reproduction in any medium or format, as long as you give appropriate credit to the original author(s) and the source, provide a link to the Creative Commons licence, and indicate if changes were made. The images or other third party material in this article are included in the article's Creative Commons licence, unless indicated otherwise in a credit line to the material. If material is not included in the article's Creative Commons licence and your intended use is not permitted by statutory regulation or exceeds the permitted use, you will need to obtain permission directly from the copyright holder. To view a copy of this licence, visit http://creativecommons. org/licenses/by/4.0/.

\section{References}

Albins MA (2013) Effects of invasive Pacific red lionfish Pterois volitans versus a native predator on Bahamian coral-reef fish communities. Biol Invasions 15:29-43

Anton A, Cure K, Layman CA, Puntila R, Simpson MS, Bruno JF (2016) Prey naiveté to invasive lionfish Pterois volitans on Caribbean coral reefs. Mar Ecol Prog Ser 544:257-269

Anton A, Geraldi NR, Lovelock CE, Apostolaki ET, Bennett S, Cebrian J, Krause-Jensen D, Marbà N, Martinetto P, Pandolfi JM, Santana-Garcon J, Duarte CM (2019) Global ecological impacts of marine exotic species. Nat Ecol Evol 3:787-800

Bellwood DR, Goatley CHR (2017) Can biological invasions save Caribbean coral reefs? Curr Biol 27:R13-R14

Benkwitt CE, Albins MA, Buch KL, Ingeman KE, Kindinger TL, Pusack TJ, Stallings CD, Hixon MA (2017) Is the lionfish invasion waning? Evidence from The Bahamas. Coral Reefs 36:1255-1261

Chapman JK, Anderson LG, Gough CLA, Harris AR (2016) Working up an appetite for lionfish: a market-based approach to manage the invasion of Pterois volitans in Belize. Mar Policy 73:256-262

Côté IM, Green SJ, Hixon MA (2013) Predatory fish invaders: insights from Indo-Pacific lionfish in the western Atlantic and Caribbean. Biol Conserv 164:50-61

Cure K, Benkwitt CE, Kindinger TL, Pickering EA, Pusack TJ, McIlwain JL, Hixon MA (2012) Comparative behavior of red lionfish Pterois volitans on native Pacific versus invaded Atlantic coral reefs. Mar Ecol Prog Ser 467:181-192

Curtis JS, Wall KR, Albins MA, Stallings CD (2017) Diet shifts in a native mesopredator across a range of invasive lionfish biomass. Mar Ecol Prog Ser 573:215-228

D'Agostino D, Jimenez C, Reader T, Hadjioannou L, Heyworth S, Aplikioti M, Argyrou M, Feary DA (2020) Behavioural traits and feeding ecology of Mediterranean lionfish and naiveté of native species to lionfish predation. Mar Ecol Prog Ser 638:123-135
Dahl KA, Patterson WF III (2014) Habitat-Specific Density and Diet of Rapidly Expanding Invasive Red Lionfish, Pterois volitans, Populations in the Northern Gulf of Mexico. PLoS ONE 9:e105852

Davis MA, Chew MK, Hobbs RJ, Lugo AE, Ewel JJ, Vermeij GJ, Brown JH, Rosenzweig ML, Gardener MR, Carroll SP, Thompson K, Pickett STA, Stromberg JC, Tredici PD, Suding KN, Ehrenfeld JG, Philip Grime J, Mascaro J, Briggs JC (2011) Don't judge species on their origins. Nature 474:153-154

Diller JL, Frazer TK, Jacoby CA (2014) Coping with the lionfish invasion: evidence that naïve, native predators can learn to help. J Exp Mar Biol Ecol 455:45-49

Doherty TS, Ritchie EG (2016) Stop jumping the gun: a call for evidence-based Invasive predator management. conserv Lett n/a$\mathrm{n} / \mathrm{a}$

Ellis R, Faletti M (2016) Native grouper indirectly ameliorates the negative effects of invasive lionfish. Mar Ecol Prog Ser 558:267-279

Elise S, Urbina-Barreto I, Boadas-Gil H, Galindo-Vivas M, Kulbicki M (2014) No detectable effect of lionfish (Pterois volitansand P. miles) invasion on a healthy reef fish assemblage in Archipelago Los Roques National Park, Venezuela. Mar Biol162:319-330

Fehr A, Krongrad L, Duscher A, Chaves L, Fleming E, Feitosa J, George A, Gloeckler K, Irvine A, Marty M, McGinty E, NagyM, Ormond C, Paullin C, Seely T, Van Heukelem L, Withers A (2012) Assessment of the lionfish invasion off Bocas Del ToroArchipelago. 12th International Coral Reef Symposium 494

Freestone AL, Ruiz GM, Torchin ME (2013) Stronger biotic resistance in tropics relative to temperate zone: effects of predation on marine invasion dynamics. Ecology 94:1370-1377

Gleditsch JM, Carlo TA (2014) Living with aliens: effects of invasive shrub honeysuckles on avian nesting. PLoS ONE 9:e107120

Green SJ, Akins JL, Côté IM (2011) Foraging behaviour and prey consumption in the Indo-Pacific lionfish on Bahamian coral reefs. Mar Ecol Prog Ser 433:159-167

Green SJ, Akins JL, Maljković A, Côté IM (2012) Invasive Lionfish Drive Atlantic Coral Reef Fish Declines. PLoS ONE 7:e32596

Green SJ, Dulvy NK, Brooks AML, Akins JL, Cooper AB, Miller S, Côté IM (2014) Linking removal targets to the ecological effects of invaders: a predictive model and field test. Ecol Appl 24:1311-1322

Green SJ, Underwood EB, Akins JL (2017) Mobilizing volunteers to sustain local suppression of a global marine invasion. Conserv Lett 10:726-735

Hackerott S, Valdivia A, Green SJ, Côté IM, Cox CE, Akins L, Layman CA, Precht WF, Bruno JF (2013) Native Predators Do Not Influence Invasion Success of Pacific Lionfish on Caribbean Reefs. PLoS ONE 8:e68259

Hackerott S, Valdivia A, Cox CE, Silbiger NJ, Bruno JF (2017) Invasive lionfish had no measurable effect on prey fish community structure across the Belizean Barrier Reef. PeerJ 5:e3270

Haines LJ, Côté IM (2019) Homing decisions reveal lack of risk perception by Caribbean damselfish of invasive lionfish. Biol Invasions 21:1657-1668

ICRI (2014) The lionfish invasion: management strategies for the Southern Caribbean Sea. International Coral Reef Initiative29th General Meeting Reporting period October 2013 - September 2014:4-5

Ingeman K (2016) Lionfish cause increased mortality rates and drive local extirpation of native prey. Mar Ecol Progess Ser 558(235):245

Ingeman KE, Albins MA, Benkwitt CE, Green SJ, Kindinger TL, Tuttle LJ, Hixon MA (2017) Resolving differences in observed impacts of invasive lionfish and clarifying advice to managers. 
Peer J Preprint 5:e3455v1. https://doi.org/10.7287/peerj.pre prints.3455v1

Lockwood JL, Robinson OJ (2014) The impacts of invasive species on coastal marine ecosystems. In: Maslo B, Lockwood JL (eds) Coastal Conservation. Cambridge University Press

Malpica-Cruz L, Chaves LCT, Côté IM (2016) Managing marine invasive species through public participation: lionfish derbies as a case study. Mar Policy 74:158-164

Marsh-Hunkin KE, Gochfeld DJ, Slattery M (2013) Antipredator responses to invasive lionfish, Pterois volitans: interspecific differences in cue utilization by two coral reef gobies. Mar Biol 160:1029-1040

McCallister M, Renchen J, Binder B, Acosta A (2018) Diel Activity Patterns and Movement of Invasive Lionfish (Pterois volitans/P. miles) in the Florida Keys Identified Using Acoustic Telemetry. Gulf Caribb Res 29:27-40

Morris JA, Akins JL (2009) Feeding ecology of invasive lionfish ( Pterois volitans ) in the Bahamian archipelago. Environ Biol Fishes 86:389

Mumby PJ, Harborne AR, Brumbaugh DR (2011) Grouper as a natural biocontrol of invasive lionfish. PLoS ONE 6:e21510

Peiffer F, Bejarano S, de Witte GP, Wild C (2017) Ongoing removals of invasive lionfish in Honduras and their effect on native Caribbean prey fishes. PeerJ 5:e3818

Pejchar L, Mooney HA (2009) Invasive species, ecosystem services and human well-being. Trends Ecol Evol 24:497-504

R Core Team (2020) R: a language and environment for statistical computing. $\mathrm{R}$ foundation for statistical computing, vienna, austria
Rittel HWJ, Webber MM (1973) Dilemmas in a general theory of planning. Policy Sci 4:155-169

Ritchie EG, Johnson CN (2009) Predator interactions, mesopredator release and biodiversity conservation. Ecol Lett 12:982-998

Sandin SA, Pacala SW (2005) Fish aggregation results in inversely density-dependent predation on continuous coral reefs. Ecology 86:1520-1530

Siegel KJ, Cabral RB, McHenry J, Ojea E, Owashi B, Lester SE (2019) Sovereign states in the Caribbean have lower socialecological vulnerability to coral bleaching than overseas territories. Proc R Soc B Biol Sci 286:20182365

Stallings CD (2009) Fishery-Independent Data Reveal Negative Effect of Human Population Density on Caribbean Predatory Fish Communities. PLoS ONE 4:e5333

Stier AC, Stallings CD, Samhouri JF, Albins MA, Almany GR (2017) Biodiversity effects of the predation gauntlet. Coral Reefs 36(2):601-606

White J, Samhouri J, Stier A, Wormald C, Hamilton S, Sandin S (2011) Synthesizing mechanisms of density dependence in reef fishes: behavior, habitat configuration, and observation scale. Ecology 91:1949-1961

Publisher's Note Springer Nature remains neutral with regard to jurisdictional claims in published maps and institutional affiliations. 